\title{
Comparative effects of norepinephrine and vasopressin on internal thoracic arterial graft flow after off-pump coronary artery bypass grafting
}

\author{
Sung Yong Park, MD, ${ }^{\mathrm{a}}$ Dae Hee Kim, MD, ${ }^{\mathrm{a}}$ Jin Soo Kim, MD, PhD, ${ }^{\mathrm{a}}$ Sang Hyun Lim, MD, PhD, ${ }^{\mathrm{b}}$ and \\ Yong Woo Hong, MD, $\mathrm{PhD}^{\mathrm{a}}$
}

\begin{abstract}
Objective: Vasoconstrictors such as norepinephrine and vasopressin are commonly used to raise the blood pressure during myocardial revascularization. The internal thoracic artery is commonly used for coronary artery grafting because of its long-term patency. However, the internal thoracic artery is a living conduit that responds to vasoactive substances. The objective of this study was to measure change in internal thoracic arterial flow after infusion of norepinephrine or vasopressin.
\end{abstract}

\begin{abstract}
Methods: Forty-one patients undergoing elective off-pump coronary artery bypass grafting participated in this study. After the median sternotomy, the left internal thoracic artery was dissected with a pedicle and grafted to the left anterior descending artery. After all anastomoses were performed and hemodynamic parameters were stable, the grafted internal thoracic arterial blood flow was measured by transit time flowmeter on the distal portion of the graft as a baseline. Norepinephrine or vasopressin was then infused until mean arterial pressure was increased to $20 \%$ of baseline. Graft flow and hemodynamic variables were measured when mean arterial pressure reached the intended level.
\end{abstract}

Results: Baseline grafted internal thoracic arterial flows were similar (norepinephrine $57.1 \pm 17.7 \mathrm{~mL} \mathrm{~min}^{-1}$, vasopressin $66.0 \pm 34.3 \mathrm{~mL} \mathrm{~min}^{-1}$ ). With norepinephrine, flow increased significantly relative to baseline $\left(77.2 \pm 31.0 \mathrm{~mL} \mathrm{~min}^{-1}\right)$; with vasopressin, it remained unchanged $\left(68.3 \pm 37.0 \mathrm{~mL} \mathrm{~min}^{-1}\right)$.

Conclusions: For patients needing vasopressor support after coronary artery bypass grafting, norepinephrine appeared superior to vasopressin because of increased internal thoracic arterial flow. (J Thorac Cardiovasc Surg $2011 ; 141: 151-4)$

Vasoactive agents, particularly vasoconstrictors such as norepinephrine or vasopressin, are commonly used in the perioperative period to elevate the mean arterial pressure in patients undergoing myocardial revascularization. The internal thoracic artery (ITA) is commonly used for coronary artery bypass grafting because of its long-term patency relative to standard saphenous vein grafts. ${ }^{1}$ The ITA, however, is a living conduit that is responsive to vasoactive substances. $^{2-8}$ Although beneficial effects of vasopressive therapy with a vasoconstrictor have been demonstrated, ${ }^{8,9}$ it has been suggested that the administration of vasoconstrictors to elevate the coronary perfusion pressure may lead to a decrease in ITA blood flow. ${ }^{7,9}$

It is important to determine whether the ITA graft flow increases in response to vasoconstrictors after myocardial

\footnotetext{
From the Departments of Anesthesiology and Pain Medicine ${ }^{\mathrm{a}}$ and Thoracic and Cardiovascular Surgery, ${ }^{\mathrm{b}}$ Ajou University of College of Medicine, Suwon, Korea. Disclosures: Authors have nothing to disclose with regard to commercial support Received for publication Aug 12, 2009; revisions received Dec 14, 2009; accepted for publication March 9, 2010; available ahead of print May 3, 2010.

Address for reprints: Yong Woo Hong, MD, PhD, Department of Anesthesiology and Pain Medicine, Ajou University College of Medicine, San 5, Wonchon-dong, Yeongtong-gu, Suwon 443-721, Korea (E-mail: ywhong7292@gmail.com). $0022-5223 / \$ 36.00$

Copyright (c) 2011 by The American Association for Thoracic Surgery doi:10.1016/j.jtcvs.2010.03.012
}

revascularization. The objective of this study was to compare ITA flows after the use of norepinephrine and vasopressin.

\section{MATERIALS AND METHODS}

This study was approved by the institutional review board, and all patients provided written, informed consent. Patients with peripheral vascular disease, chronic significant arrhythmia, left ventricular ejection fraction less than $35 \%$, or mitral regurgitation more than grade 2 were excluded from the study. Patients who were receiving inotropic agents were also excluded.

Forty-one patients undergoing elective off-pump coronary artery bypass grafting participated in this study. Before surgery, the patients were randomly allocated to receive norepinephrine or vasopressin. Norepinephrine and vasopressin infusions were prepared by another researcher not involved in the patient care. Both the surgeon and the attending anesthesiologist were blinded to the allocation of patients to receive norepinephrine or vasopressin. There were no significant differences in demographic characteristics between the groups. The demographic data are presented in Table 1.

Preoperative medications were continued until the morning of surgery. All patients were medicated in advance with intramuscular morphine $\left(0.05-0.1 \mathrm{mg} \mathrm{kg}^{-1}\right)$. Five electrocardiographic leads were placed, and leads II and V 5 were continuously monitored. The arterial pressure was monitored with a radial artery catheter placed in the dominant hand. A pulmonary arterial catheter (Swan-Ganz CCOmbo-CC0/SvO2, Edwards Lifesciences LLC, Irvine, Calif) was inserted in the right internal jugular vein to monitor several cardiac performance parameters continuously, including central venous pressure (CVP), pulmonary artery pressure (PAP), cardiac output, and right ventricular volumetric parameters. All patients then received general anesthesia consisting of sufentanil and midazolam and supplemented by sevoflurane in an oxygen and air mixture. Vecuronium bromide was used 


\section{Abbreviations and Acronyms \\ $\mathrm{CVP}=$ central venous pressure \\ ITA $=$ internal thoracic artery \\ $\mathrm{MAP}=$ mean arterial pressure \\ $\mathrm{PAP}=$ pulmonary arterial pressure}

for muscle relaxation. Transesophageal echocardiography was used to monitor global and regional left ventricular function from the short-axis transgastric view.

After median sternotomy, the left ITA was dissected with a pedicle. To minimize vasospasm, papaverine was injected into the adventitia of the ITA. After the ITA dissection, heparin was injected intravenously. In all cases the ITA was grafted to the distal left anterior descending coronary artery.

After all the anastomoses had been performed, the protamine infusion was finished, and the patient was in hemodynamically stable condition, baseline grafted ITA blood flow was measured with a transit-time flowmeter (flash probe; Transonic Systems Inc, Ithaca, NY) on the distal portion of the graft body and hemodynamic data, including the cardiac index, heart rate, mean arterial pressure (MAP), mean PAP, CVP, and pulmonary capillary wedge pressure were collected.

After the procedure was completed, the continuous infusion of norepinephrine or vasopressin was started. The concentrations of norepinephrine $\left(8 \mu \mathrm{g} \mathrm{mL}^{-1}\right)$ and vasopressin $\left(0.2 \mathrm{U} \mathrm{mL}^{-1}\right)$ were chosen so that the starting infusion volume was $10 \mathrm{~mL} \mathrm{~h}^{-1}$. During the study, the drugs were titrated (infusion increased by $10 \mathrm{~mL} \mathrm{~h}^{-1}$ every 5-10 minutes) to maintain an approximately $20 \%$ increase in MAP according to an independent anesthesiologist blinded to the type of drug that was administered. The graft flow measurements and hemodynamic variables were repeated as described previously.

All data are expressed as mean \pm SD or number of patients. Sample-size calculation was performed according to the results of a preliminary study under the following assumptions: an $80 \%$ power to detect a $10 \%$ difference in the change of ITA graft blood from the baseline value and an $\alpha$ level of .05 . These assumptions generated an estimate of 16 patients in each group. Demographic data were analyzed with the unpaired $t$ test. Comparison of means within the groups was performed with the paired $t$ test. The changes in the ITA graft blood flow and hemodynamic variables were compared between the groups with an unpaired $t$ test. All analyses were conducted with SPSS version 13.0 (SPSS Inc, an IBM Company, Chicago, Ill).

\section{RESULTS}

In the norepinephrine group, the administration of norepinephrine increased the MAP from $71.8 \pm 5.4 \mathrm{~mm} \mathrm{Hg}$ to $85.8 \pm 6.2 \mathrm{~mm} \mathrm{Hg}(P<.001)$ and the systemic vascular resistance index from $2325.8 \pm 593.6$ dyne $\cdot \mathrm{s} \cdot \mathrm{m}^{2} \cdot \mathrm{cm}^{-5}$ to $2639.0 \pm 515.5$ dyne $\cdot \mathrm{s} \cdot \mathrm{m}^{2} \mathrm{~cm}^{-5}(P=.020)$ and decreased the CVP from $6.7 \pm 1.8 \mathrm{~mm} \mathrm{Hg}$ to $6.4 \pm 1.6 \mathrm{~mm} \mathrm{Hg}$ $(P=.031)$. No significant changes in the heart rate, mean PAP, cardiac index, and peripheral vascular resistance index were observed (Table 2).

In the vasopressin group, vasopressin infusion increased the MAP from $72.1 \pm 5.1 \mathrm{~mm} \mathrm{Hg}$ to $86.1 \pm 5.5 \mathrm{~mm} \mathrm{Hg}(P<.001)$ and the systemic vascular resistance index from $2353.5 \pm$ 711.9 dyne $\cdot \mathrm{s} \cdot \mathrm{m}^{2} \cdot \mathrm{cm}^{-5}$ to $2643.0 \pm 662.0$ dyne $\cdot \mathrm{s} \cdot \mathrm{m}^{2}$ $\cdot \mathrm{cm}^{-5}(P=.011)$ and decreased the peripheral vascular resistance index from $223.5 \pm 59.2 \mathrm{dyne} \cdot \mathrm{s} \cdot \mathrm{m}^{2} \cdot \mathrm{cm}^{-5}$ to $193.3 \pm$
60.4 dyne $\cdot \mathrm{s} \cdot \mathrm{m}^{2} \cdot \mathrm{cm}^{-5}(P=.007)$. There were no significant changes in heart rate, mean PAP, CVP, and cardiac index (Table 2). There were no significant differences in hemodynamic variables between the treatment groups.

The baseline grafted ITA flows were similar in the treatment groups (norepinephrine $57.1 \pm 17.7 \mathrm{~mL} \mathrm{~min}^{-1}$ vs vasopressin $66.0 \pm 34.3 \mathrm{~mL} \mathrm{~min}^{-1}$ ). In the norepinephrine group, ITA flow increased from $57.1 \pm 17.7 \mathrm{~mL} \mathrm{~min}^{-1}$ to $77.2 \pm$ $31.0 \mathrm{~mL} \mathrm{~min}^{-1}(P=.015)$, whereas in the vasopressin group, it remained unchanged $\left(66.0 \pm 34.3 \mathrm{~mL} \mathrm{~min}^{-1}\right.$ vs $68.3 \pm$ $37.0 \mathrm{~mL} \mathrm{~min}^{-1}$; Table 2).

\section{DISCUSSION}

In this study, we found that the administration of norepinephrine increased the blood flow of the grafted ITA. In contrast, the infusion of vasopressin did not induce any significant change in the grafted ITA blood flow.

The ITA is ideally suited for coronary artery grafting. Histologically, the ITA is composed of a thin-walled media and a well-formed internal elastic lamina. These properties may be responsible for its long-term patency and low susceptibility to atherosclerosis relative to grafts from the saphenous vein. ${ }^{10}$ The ITA, however, is a living conduit that reacts to vasoactive drugs. ${ }^{2-8,10}$ Once the ITA has been grafted, flow is influenced by the downstream resistance as well as by the effects of endogenous or exogenous vasoconstrictors on the ITA itself. ${ }^{5}$

Graft flow is dependent not only on the effects of vasoactive drug on the conduit but also on the effects of vasoactive drugs on the regional vasculature, coronary vasculature, or a combination. ${ }^{7}$ Once anastomosed, the ITA functions as an epicardial coronary artery and is subject to all the determinants of coronary flow, such as heart rate, aortic pressure, left ventricular pressure, and coronary vascular resistance. ${ }^{5}$ In addition, the ITA has been shown to be a dynamic conduit capable of enlarging to meet the metabolic demands of its coronary vascular bed. ${ }^{6,7}$ There is a report that Y-graft blood flow is also significantly increased in response to increased myocardial oxygen demand. ${ }^{11}$

Graft flow immediately after myocardial revascularization has received less attention than long-term patency. It is in the immediate postgraft period, however, that most hemodynamic instability occurs. As the MAP decreases, there is a disproportionate reduction in arterial graft flow. ${ }^{8}$ Hypotension should be corrected immediately by cessation of vasodilator therapy or the addition of an appropriate vasoconstrictor. The use of a vasoconstrictor to counteract the hypotension may occasionally reduce the ITA blood flow as a result of graft vessel vasoconstriction; however, restoration of a normal MAP pressure is of more importance than the potential loss of blood flow through the vasoconstriction. ${ }^{4,9}$

Norepinephrine is a potent $\alpha$-adrenergic vasoconstrictor and a relatively mild $\beta$-adrenergic agonist that has positive inotropic and chronotropic effects. Whereas less than 
TABLE 1. Patient characteristics

\begin{tabular}{lcc}
\hline & $\begin{array}{c}\text { Norepinephrine } \\
(\mathbf{n}=\mathbf{2 0})\end{array}$ & $\begin{array}{c}\text { Vasopressin } \\
(\mathbf{n}=\mathbf{2 1})\end{array}$ \\
\hline Age $(\mathrm{y}$, mean $\pm \mathrm{SD})$ & $62.0 \pm 9.3$ & $60.7 \pm 8.6$ \\
Sex $($ male/female ratio) & $11: 9$ & $17: 4$ \\
Weight $(\mathrm{kg}$, mean $\pm \mathrm{SD})$ & $66.5 \pm 8.6$ & $69.2 \pm 9.9$ \\
Height $(\mathrm{cm}$, mean $\pm \mathrm{SD})$ & $162.0 \pm 9.4$ & $166.6 \pm 7.5$ \\
Body surface area $\left(\mathrm{m}^{2}\right.$, mean $\left.\pm \mathrm{SD}\right)$ & $1.7 \pm 0.1$ & $1.8 \pm 0.1$ \\
\hline There were no statistically significant differences between groups. &
\end{tabular}

$2 \mu \mathrm{g} / \mathrm{min}$ may uncover the effects of $\beta$-adrenergic stimulation, the usual infusion rates of greater than $3 \mu \mathrm{g} / \mathrm{min}$ elicit peripheral vasoconstriction from $\alpha$-adrenergic stimulation. ${ }^{12}$ The marked pressor effects are primarily due to increased peripheral vascular resistance mediated through both the $\alpha_{1}$ and $\alpha_{2}$ postsynaptic receptors. During the precise control of cardiac output and blood pressure, which were maintained at constant levels during drug infusion to isolate the effects of the drug on the ITA conduit, norepinephrine did not alter the ITA blood flow. ${ }^{6}$ Conversely, Jett and colleagues ${ }^{7}$ demonstrated that norepinephrine increases the ITA blood flow, with concomitant increase in the rate of left ventricular pressure that represented an increase in myocardial oxygen consumption. Their study is consistent with our results. It is considered that norepinephrine increases the ITA graft blood flow through increased myocardial oxygen demand and perfusion pressure.

Vasopressin, a hypothalamic hormone stored and released by the neurohypophysis, has marked vasoconstrictor effect ${ }^{13}$ and has recently gained attention as a possible tool against septic shock and vasodilation states associated with cardiac anesthesia and surgery; therefore, it is also used during the postgraft hypotensive state., ${ }^{2,14}$ Although some studies have suggested that vasopressin improves vital organ blood flow, including cerebral and coronary blood flow, during cardiopulmonary resuscitation by increasing perfusion pressure, ${ }^{15-18}$ the results of in vitro studies have suggested that ITA is constricted by vasopressin. ${ }^{19}$ Thus vasopressin has been considered to provoke graft vessel spasm. ${ }^{9,19}$ Although vasopressin is known to be associated with coronary vasoconstriction, few studies have been conducted to evaluate its effects on ITA blood flow in vivo. ${ }^{2,9}$ In this study, vasopressin infusion did not change the grafted ITA blood flow, despite the increased myocardial oxygen consumption. These results suggest that ITA vasoconstriction caused by vasopressin infusion could be more potent than that caused by norepinephrine infusion.

In addition to information regarding the grafted ITA blood flow, in this study vasopressin decreased the peripheral vascular resistance index. To date, few studies have been conducted to evaluate peripheral vascular resistance, and the described effects of vasopressin on pulmonary vessels have not been consistent. ${ }^{20-23}$ On the basis of the results of this study and previous studies, ${ }^{21-23}$ we speculate that vasopressin is favorable for treating low systemic vascular resistance hypotension with pulmonary hypertension.

In addition to the effects of norepinephrine and vasopressin on the ITA, there is ample reason to think that other factors may influence the graft flow. The ITA is a dynamic coronary graft, whereas the saphenous vein graft is passive. Measurement of saphenous vein graft flow thus might help to shed light on the site of action in this study. In a previous study, ${ }^{6}$ norepinephrine increased flows in both ITA and saphenous vein grafts with similar patterns. In the cases of vasopressin, however, there has been no study regarding saphenous vein graft flow.

It should be noted that this study has some limitations. First, the transit-time Doppler probes used are accurate but sensitive to differences in angle, which is sometimes difficult to control when the heart and the lungs are moving. Because operator-dependent measurement errors were possible, the same operator measured the graft flow whenever possible, and the operator was blinded to the allocation of the study drug. Second, anesthetic agents, especially inhalational agents, can induce grafted ITA vasodilation. To minimize factors that affect vessel tone, anesthetic agents (narcotic plus inhalational agent) were controlled throughout the

TABLE 2. Hemodynamics and internal thoracic arterial flows after norepinephrine and vasopressin

\begin{tabular}{|c|c|c|c|c|}
\hline & \multicolumn{2}{|c|}{ Norepinephrine } & \multicolumn{2}{|c|}{ Vasopressin } \\
\hline & Baseline & After drug & Baseline & After drug \\
\hline Heart rate (beats $\min ^{-1}$ ) & $71.0 \pm 13.0$ & $71.7 \pm 12.8$ & $69.9 \pm 11.4$ & $68.9 \pm 11.6$ \\
\hline Mean arterial pressure $(\mathrm{mm} \mathrm{Hg})$ & $71.8 \pm 5.4$ & $85.8 \pm 6.2^{*}$ & $72.1 \pm 5.1$ & $86.1 \pm 5.5^{*}$ \\
\hline Mean pulmonary arterial pressure $(\mathrm{mm} \mathrm{Hg})$ & $17.4 \pm 2.9$ & $17.3 \pm 2.4$ & $17.9 \pm 5.0$ & $17.5 \pm 5.5$ \\
\hline Central venous pressure $(\mathrm{mm} \mathrm{Hg})$ & $6.7 \pm 1.8$ & $6.4 \pm 1.6^{*}$ & $6.1 \pm 2.4$ & $5.9 \pm 2.1$ \\
\hline \multicolumn{5}{|l|}{ Resistance index $\left(\right.$ dyne $\left.\cdot \mathrm{s} \cdot \mathrm{m}^{2} \cdot \mathrm{cm}^{-5}\right)$} \\
\hline Systemic & $2325.8 \pm 593.6$ & $2639.0 \pm 515.5^{*}$ & $2353.5 \pm 711.9$ & $2643.0 \pm 662.0^{*}$ \\
\hline Pulmonary & $195.6 \pm 72.6$ & $199.1 \pm 72.6$ & $223.5 \pm 59.2$ & $193.3 \pm 60.4^{*}$ \\
\hline Cardiac index $\left(\mathrm{L}\left[\min \mathrm{m}^{2}\right]^{-1}\right)$ & $2.4 \pm 0.6$ & $2.5 \pm 0.4$ & $2.4 \pm 0.7$ & $2.5 \pm 0.6$ \\
\hline Internal thoracic arterial flow $\left(\mathrm{mL} \mathrm{min}^{-1}\right)$ & $57.1 \pm 17.7$ & $77.2 \pm 31.0^{*}$ & $66.0 \pm 34.3$ & $68.3 \pm 37.0$ \\
\hline
\end{tabular}

All values are expressed as mean \pm SD. $* P<.05$ versus baseline. 
study period. In addition, the study was performed after control of bleeding and hemodynamic stability had been achieved. Third, doses of the vasoconstrictors were not evaluated in this study. The creative aspect of this study design was that elevation of MAP to the intended level was considered as the pharmacodynamic end point. In previous studies regarding graft blood flow change after drug administration, infusion rates of study drugs were predetermined. ${ }^{3-7}$ Elevation of perfusion pressure was thus not achieved in some studies. ${ }^{5-7}$ In this study, because the elevation of MAP during vasoconstrictor infusion was considered as the pharmacodynamic end point, only a starting dose was selected and doses were escalated until the intended MAP level had been achieved. The influence of doses of vasoconstrictor on ITA grafts needs further investigation.

\section{CONCLUSIONS}

Systemic hypotension is common during coronary revascularization surgery. A vasoconstrictor is frequently needed to correct the hypotension, despite grafted vessel constriction. Thus the vascular reactivity of the ITA must be taken into consideration when vasoconstrictors are used after coronary revascularization. This study demonstrates that for patients needing vasopressor support after coronary revascularization, norepinephrine appears to be superior to vasopressin because of the increase in ITA blood flow.

\section{References}

1. Loop FD, Lytle BW, Cosgrove DM, Stewart RW, Goormastic M, Williams GW, et al. Influence of the internal-mammary-artery graft on 10-year survival and other cardiac events. N Engl J Med. 1986;314:1-6.

2. Novella S, Martínez AC, Pagán RM, Hernández M, García-Sacristán A, González-Pinto A, et al. Plasma levels and vascular effects of vasopressin in patients undergoing coronary artery bypass grafting. Eur J Cardiothorac Surg. 2007;32:69-76.

3. Na S, Oh YJ, Shim YH, Hong YW, Bang SO, Kwak YL. Effects of milrinone on blood flow of the Y-graft composed with the radial and the internal thoracic artery in patients with coronary artery disease. Eur J Cardiothorac Surg. 2006;30:324-8.

4. Lobato EB, Janelle GM, Urdaneta F, Martin TD. Comparison of milrinone versus nitroglycerin, alone and in combination, on grafted internal mammary artery flow after cardiopulmonary bypass: effects of alpha-adrenergic stimulation. J Cardiothorac Vasc Anesth. 2001;15:723-7.

5. Lobato EB, Urdaneta F, Martin TD, Gravenstein N. Effects of milrinone versus epinephrine on grafted internal mammary artery flow after cardiopulmonary bypass. J Cardiothorac Vasc Anesth. 2000;14:9-11.
6. Gitter R, Anderson JM Jr, Jett GK. Influence of milrinone and norepinephrine on blood flow in canine internal mammary artery grafts. Ann Thorac Surg. 1996;61: 1367-71.

7. Jett GK, Arcidi JM Jr, Dorsey LM, Hatcher CR Jr, Guyton RA. Vasoactive drug effects on blood flow in internal mammary artery and saphenous vein grafts. J Thorac Cardiovasc Surg. 1987;94:2-11.

8. Beavis RE, Mullany CJ, Cronin KD, Scott DA, Treagus BC, Zhikun Y, et al. An experimental in vivo study of the canine internal mammary artery and its response to vasoactive drugs. J Thorac Cardiovasc Surg. 1988;95:1059-66.

9. Rosenfeldt FL, He GW, Buxton BF, Angus JA. Pharmacology of coronary artery bypass grafts. Ann Thorac Surg. 1999;67:878-88.

10. Janelle GM, Urdaneta F, Martin TD, Lobato EB. Effects of calcium chloride on grafted internal mammary artery flow after cardiopulmonary bypass. $J$ Cardiothorac Vasc Anesth. 2000;14:4-8.

11. He GW, Angus JA, Rosenfeldt FL. Reactivity of the canine isolated internal mammary artery, saphenous vein, and coronary artery to constrictor and dilator substances: relevance to coronary bypass graft surgery. J Cardiovasc Pharmacol. 1988; 12:12-22.

12. Jonathan M, David G. The autonomic nervous system. In: Miller RD, ed. Miller's anesthesia. 6th ed. Philadelphia: Elsevier; 2005:649.

13. Treschan TA, Peters J. The vasopressin system: physiology and clinical strategies. Anesthesiology. 2006;105:599-612.

14. Sanjay OP, Kilpadi K, Prashanth P, Vincent V, Thejas BC. Use of arginine vasopressin in the management of vasodilatory shock after CABG_-a clinical trial. Ann Card Anaesth. 2003;6:132-5.

15. Morris DC, Dereczyk BE, Grzybowski M, Martin GB, Rivers EP, Wortsman J, et al. Vasopressin can increase coronary perfusion pressure during human cardiopulmonary resuscitation. Acad Emerg Med. 1997;4:878-83.

16. Wenzel V, Lindner KH, Prengel AW, Maier C, Voelckel W, Lurie KG, et al. Vasopressin improves vital organ blood flow after prolonged cardiac arrest with postcountershock pulseless electrical activity in pigs. Crit Care Med. 1999;27: 486-92.

17. Wenzel V, Lindner KH, Krismer AC, Miller EA, Voelckel WG, Lingnau W. Repeated administration of vasopressin but not epinephrine maintains coronary perfusion pressure after early and late administration during prolonged cardiopulmonary resuscitation in pigs. Circulation. 1999;99:1379-84.

18. Johansson J, Gedeborg R, Rubertsson S. Vasopressin versus continuous adrenaline during experimental cardiopulmonary resuscitation. Resuscitation. 2004;62: $61-9$.

19. Wei W, Floten HS, He GW. Interaction between vasodilators and vasopressin in internal mammary artery and clinical significance. Ann Thorac Surg. 2002;73: 516-22.

20. Mols P, Hallemans R, Van Kuyk M, Melot C, Lejeune P, Ham H, et al. Hemodynamic effects of vasopressin, alone and in combination with nitroprusside, in patients with liver cirrhosis and portal hypertension. Ann Surg. 1984;199:176-81.

21. Altintas E, Akkus N, Gen R, Helvaci MR, Sezgin O, Oguz D. Effects of terlipressin on systolic pulmonary artery pressure of patients with liver cirrhosis: an echocardiographic assessment. World J Gastroenterol. 2004;10:2278-80.

22. Evora PR, Pearson PJ, Schaff HV. Arginine vasopressin induces endotheliumdependent vasodilatation of the pulmonary artery. V1-receptor-mediated production of nitric oxide. Chest. 1993;103:1241-5.

23. Jeon Y, Ryu JH, Lim YJ, Kim CS, Bahk JH, Yoon SZ, et al. Comparative hemodynamic effects of vasopressin and norepinephrine after milrinoneinduced hypotension in off-pump coronary artery bypass surgical patients. Eur J Cardiothorac Surg. 2006;29:952-6. 